\title{
The challenge of medication errors in the emergency department setting
}

\author{
Mojtaba Miladinia ${ }^{1,2^{*}}{ }^{(\mathbb{D}}$, Elham Mousavi Nouri ${ }^{(\mathbb{D}}$ \\ ${ }^{1}$ Nursing Care Research Center in Chronic Diseases, School of Nursing \& Midwifery, Ahvaz Jundishapur University of Medical \\ Sciences, Ahvaz, Iran \\ ${ }^{2}$ Student Research Committee, Ahvaz Jundishapur University of Medical Sciences, Ahvaz, Iran \\ ${ }^{3}$ Emergency Clinical Nurse, Ahvaz Jundishapur University of Medical Sciences, Ahvaz, Iran
}

\section{Dear Editor,}

Medication errors (MEs) are considered as the most common medical errors causing major challenges which can threaten the health system. If proper actions are taken into account they can be reduced. MEs threaten patients' safety and may increase the length of hospital stay, lead to unexpected complications, mortality and additional costs $(1,2)$. In 2017, the World Health Organization (WHO) launched 'Medication without Harm' to reduce severe avoidable medication-related damage by $50 \%$, globally in the next 5 years (3). Emergency departments (EDs) are stressful care environments characterized by high speed performance, a large number of patients, unpredictability, high workload, availability of various medications and oral instructions, making EDs more prone to MEs. In addition, the critical nature of many emergency patients may lead to MEs. Therefore, EDs need to be seriously considered to reduce MEs and increase patients' safety. A review of literature on MEs in EDs provides us with important background knowledge which is helpful in future planning. In this regard, it is of great significance to know about the most common stages of error in pharmacotherapy, the most common types of $\mathrm{ME}$ and the most common causes of MEs in the emergency department practice setting.

\section{Stages of the MEs in EDs}

There are five consecutive stages in the pharmacotherapy: 1) prescribing, 2) transcribing, 3) dispensing, 4) administration, and 5) monitoring. Errors may occur in each stage. A review of literature on MEs in EDs (three national and two international studies) shows that the administration and prescribing are the most common stages of error. In the administration and prescribing stages, the error usually occurs by the nurse and by the physician, respectively (4-8). Thus, these two stages should be considered as the main purpose of the future studies and planning. Also, in planning nurses should be given more attention.

\section{Types of MEs in EDs}

More than 20 types of MEs may occur (Table 1). A review of literature on MEs in EDs (five national and five international studies) shows that the most common types of MEs in EDs include drug omission error, wrong dose and strong infusion rate (4,5,8-15). Therefore, focusing, planning and training clinicians on these three types of MEs may greatly reduce the amount of MEs in EDs.

\section{Causes of the MEs in EDs (in Iran)}

A review of four national studies reveals that, according to the perspective of clinicians, the most common causes of MEs in EDs include nursing shortage (fatigue) and poor medication knowledge $(5,9,14,16)$. Hence, MEs in EDs can be greatly prevented by planning to reduce these two causes. Strategies for employing experienced nurses in EDs, establishing ways for contacting a clinical pharmacist, holding regular retraining courses, improving nurses' pharmacological knowledge during undergraduate courses, as well as conducting interventional studies to reduce MEs in EDs can be helpful.

Received: 20 April 2021 Accepted: 3 June 2021 Published online: 17 June 2021

*Corresponding author: Mojtaba Miladinia, Faculty Member, Nursing Care Research Center in Chronic Diseases, School of Nursing \& Midwifery, Ahvaz Jundishapur University of Medical Sciences, Ahvaz, Iran. Tel:+98 61 33335377; Email: miladinia.m@ajums.ac.ir

Competing interests: Not declared.

Funding information: None.

Citation: Miladinia M, Mousavi Nouri E. The challenge of medication errors in the emergency department setting. Journal of Emergency Practice and Trauma 2022; 8(1): 1-2. doi: 10.34172/jept.2021.19. 
Table 1. Types of medication errors

\begin{tabular}{ll}
\hline Wrong dose & Wrong diluent \\
\hline Wrong drug & Given medication of 2 doses at one time \\
\hline Wrong patient & Wrong date \\
\hline Wrong administration technique & Wrong documentation \\
\hline Drug omission error & Wrong route \\
\hline Wrong drug & Unauthorized drug error \\
\hline Wrong infusion rate & Deteriorated drug error \\
\hline Extra dose & Wrong dosage-form \\
\hline Wrong drug preparation & Drug-drug interaction \\
\hline Wrong time & other \\
\hline
\end{tabular}

\section{Authors' contributions}

Authors contributed equally to the work.

\section{Ethical issues}

Not applicable.

\section{Acknowledgements}

None.

\section{References}

1. Miladinia M, Zarea K, Baraz S, Mousavi Nouri E, Pishgooie AH, Gholamzadeh Baeis M. Pediatric nurses' medication error: the self-reporting of frequency, types and causes. Int J Pediatr 2016; 4(3): 1439-44. doi: 10.22038/ijp.2016.6593.

2. Asadi P, Modirian E, Dadashpour N. Medical errors in emergency department; a letter to editor. Emerg (Tehran) 2018; 6(1): e33.

3. World Health Organization (WHO). The third WHO Global Patient Safety Challenge: Medication Without Harm. WHO; 2017. Available from: https://www.who.int/ patientsafety/medication-safety/en/.

4. Dabaghzadeh F, Rashidian A, Torkamandi H, Alahyari S, Hanafi S, Farsaei S, et al. Medication errors in an emergency department in a large teaching hospital in Tehran. Iran J Pharm Res 2013; 12(4): 937-42.

5. Vazin A, Zamani Z, Hatam N. Frequency of medication errors in an emergency department of a large teaching hospital in southern Iran. Drug Healthc Patient Saf 2014; 6: 179-84. doi: 10.2147/dhps.s75223.

6. Flynn EA, Barker K, Barker B. Medication-administration errors in an emergency department. Am J Health Syst Pharm 2010; 67(5): 347-8. doi: 10.2146/ajhp090623.

7. Pérez-Díez C, Real-Campaña JM, Noya-Castro MC, Andrés-Paricio F, Reyes Abad-Sazatornil M, Bienvenido Povar-Marco J. [Medication errors in a hospital emergency department: study of the current situation and critical points for improving patient safety]. Emergencias 2017; 29(6): 412-5.

8. Zeraatchi A, Talebian MT, Nejati A, Dashti-Khavidaki $S$. Frequency and types of the medication errors in an academic emergency department in Iran: the emergent need for clinical pharmacy services in emergency departments. J Res Pharm Pract 2013; 2(3): 118-22. doi: 10.4103/2279042x.122384.

9. Ehsani SR, Cheraghi MA, Nejati A, Salari A, Haji Esmaeilpoor A, Mohammad Nejad E. Medication errors of nurses in the emergency department. J Med Ethics Hist Med 2013; 6: 11.

10. Shitu Z, Aung MMT, Tuan Kamauzaman TH, Ab Rahman AF. Prevalence and characteristics of medication errors at an emergency department of a teaching hospital in Malaysia. BMC Health Serv Res 2020; 20(1): 56. doi: 10.1186/s12913020-4921-4.

11. Selbst SM, Fein JA, Osterhoudt K, Ho W. Medication errors in a pediatric emergency department. Pediatr Emerg Care 1999; 15(1): 1-4. doi: 10.1097/00006565-199902000-00001.

12. Stasiak P, Afilalo M, Castelino T, Xue X, Colacone A, Soucy $\mathrm{N}$, et al. Detection and correction of prescription errors by an emergency department pharmacy service. CJEM 2014; 16(3): 193-206. doi: 10.2310/8000.2013.130975.

13. Rothschild JM, Churchill W, Erickson A, Munz K, Schuur JD, Salzberg CA, et al. Medication errors recovered by emergency department pharmacists. Ann Emerg Med 2010; 55(6): 513-21. doi: 10.1016/j.annemergmed.2009.10.012.

14. Mohammad Nejad E, Ehsani SR, Salari A, Sajjadi A, Haji Esmaeilpoor A. Refusal in reporting medication errors from the perspective of nurses in emergency ward. Journal of Research Development in Nursing and Midwifery 2013; 10(1): 61-8. [Persian].

15. Macías Maroto M, Solís Carpintero L. [Medication administration errors at an emergency service: knowing to decrease risk]. Rev Esp Salud Publica 2018; 92.

16. Salavati S, Hatamvand F, Tabesh H, Salehi Nasab M. nurses' perspectives on causes of medication errors and nonreporting at ED. Iran Journal of Nursing 2012; 25(79): 72 83. [Persian]. 